\title{
Ambient Temperature RAFT Polymerization of Styrene and Its Functional Derivatives under Mild Long-Wave UV-Visible Radiation
}

\author{
Haijia Zhang, Junjie Deng, Lican Lu, and Yuanli Cai*
}

Key Laboratory of Environmentally Friendly Chemistry and Applications of Ministry of Education, College of Chemistry, Xiangtan University, Xiangtan, Hunan 411105, P. R. China

\section{Supporting Information}




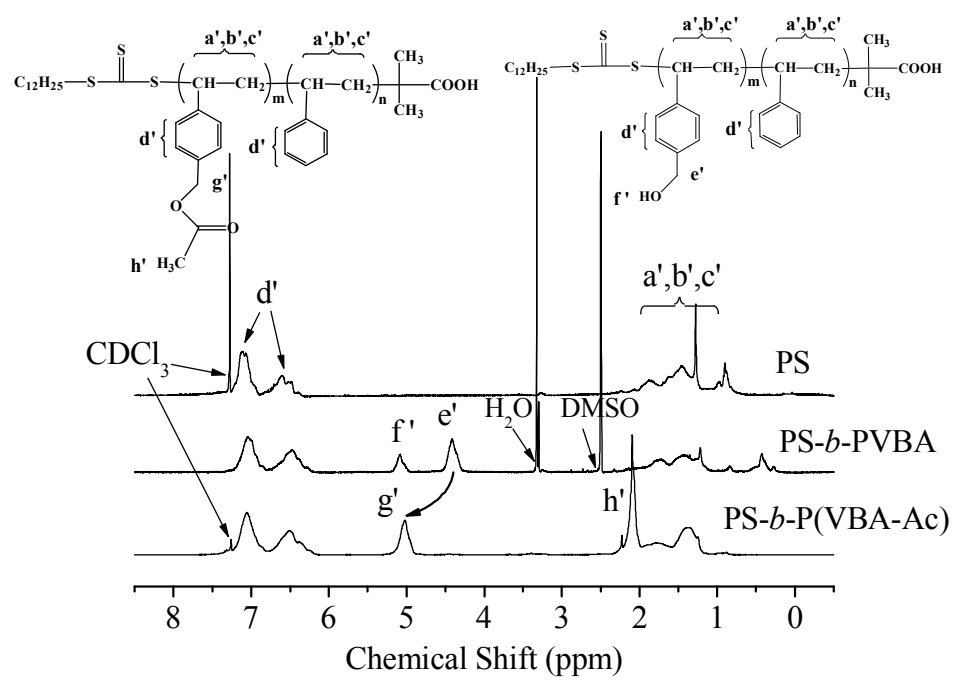

(a)

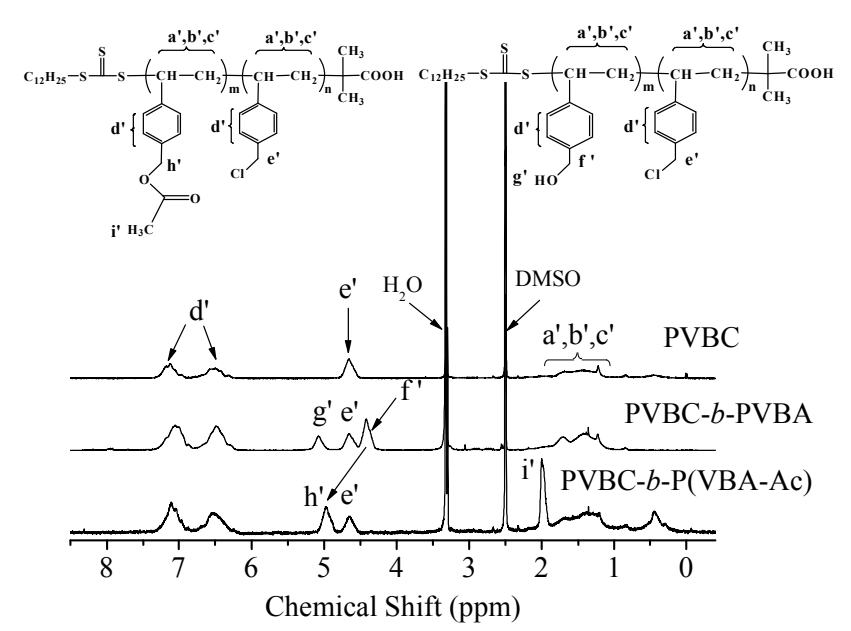

(b)

Figure S1 (a) ${ }^{1} \mathrm{H}$ NMR spectra of polystyrene (PS) macro-CTA and its corresponding polystyrene-block-poly(vinylbenzyl alcohol) (PS-b-PVBA) and acetic-anhydride-capped PS- $b$-PVBA; (b) ${ }^{1} \mathrm{H}$ NMR spectra of poly(vinylbenzyl chloride) (PVBC) macro-CTA and its corresponding poly(vinylbenzyl chloride)-block-poly(vinylbenzyl alcohol) (PVBC- $b$-PVBA) and acetic-anhydride-capped PVBC- $b$-PVBA. The complete disappearance of the proton resonance signals e' $\left(\mathrm{PhC} \underline{\mathbf{H}}_{2} \mathrm{OH}\right)$ in Figure $\mathrm{S} 1(\mathrm{a})$ and f' $\left(\mathrm{PhC} \underline{\mathbf{H}}_{2} \mathrm{OH}\right)$ in Figure $\mathrm{S} 1(\mathrm{~b})$ confirmed that hydroxyl groups of these block copolymers were essentially capped by acetic anhydride 


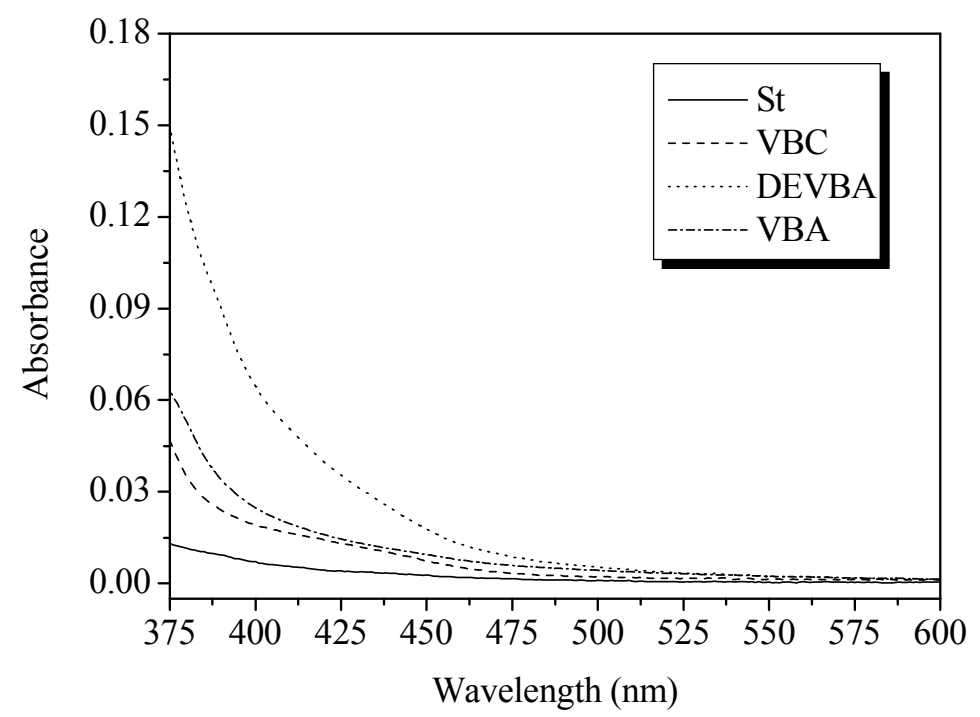

Figure S2 UV-vis spectra of $2.0 \mathrm{~mol} \mathrm{~L}^{-1}$ styrene (St), 4-vinylbenzyl chloride (VBC), 4-vinylbenzyl alcohol (VBA) and $N, N$-diethyl vinylbenzylamine (DEVBA) respectively, in tetrahydrofuran 


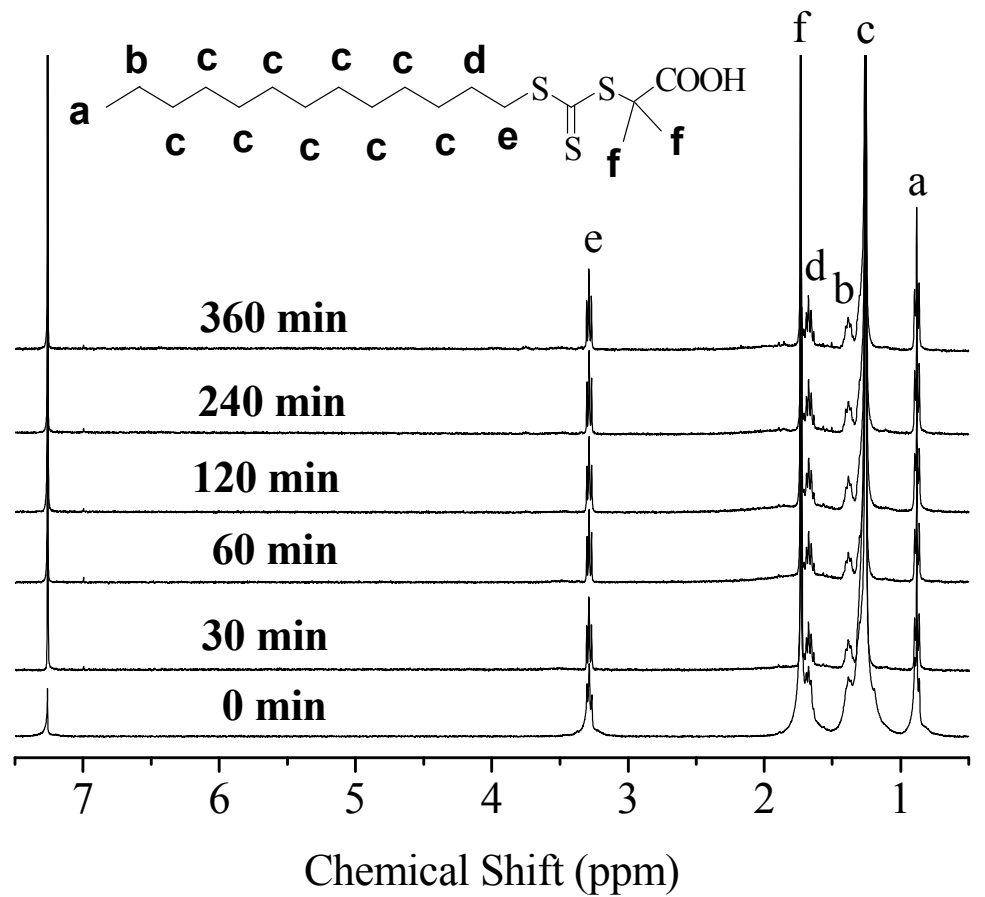

Figure $\mathbf{S 3}{ }^{1} \mathrm{H}$ NMR spectra of S-1-dodecyl-S'-( $\alpha, \alpha^{\prime}$-dimethyl- $\alpha$ "-acetic acid) trithiocarbonate (DDMAT) distilled from $25 \mathrm{mmol} \mathrm{L}^{-1}$ deoxygenated DDMAT solutions in tetrahydrofuran under long-wave radiation with intensity of $100 \mu \mathrm{W} \mathrm{cm}{ }^{-2}$ at $365 \mathrm{~nm}$ and $80 \mu \mathrm{W} \mathrm{cm}^{-2}$ at $420 \mathrm{~nm}$ at $30{ }^{\circ} \mathrm{C}$ at predetermined intervals 


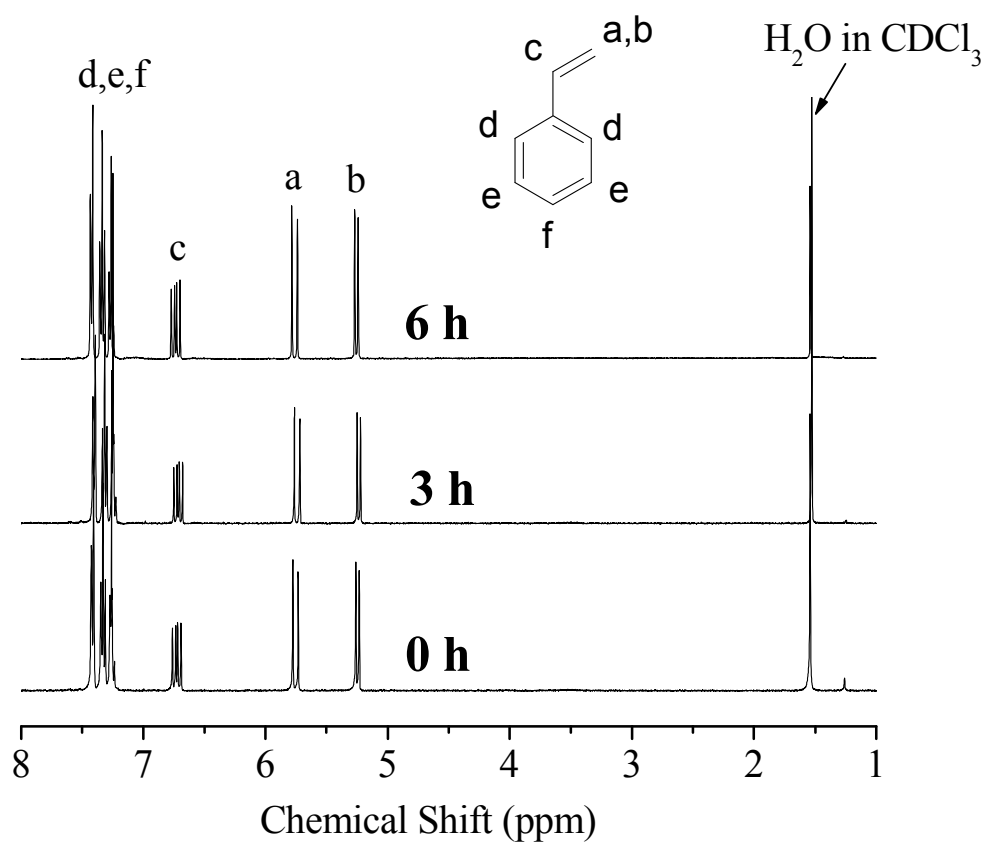

Figure S4 ${ }^{1}$ H NMR spectra of deoxygenated bulky styrene under long-wave radiation with intensity of $100 \mu \mathrm{W} \mathrm{cm}{ }^{-2}$ at $365 \mathrm{~nm}$ and $80 \mu \mathrm{W} \mathrm{cm}{ }^{-2}$ at $420 \mathrm{~nm}$ at $30{ }^{\circ} \mathrm{C}$ at predetermined intervals 